\title{
Discovery of the ARP2 protein as a determining molecule in tumor cell death
}

\author{
Juana Virginia Tapia-Vieyra and Jaime Mas-Oliva* \\ Universidad Nacional Autónoma de México, Institute of Cell Physiology, Mexico City, Mexico
}

\begin{abstract}
\end{abstract}
Cancer is a multifactorial disease that constitutes a serious public health problem worldwide. Prostate cancer advanced stages are associated with the development of androgen-independent tumors and an apoptosis-resistant phenotype that progresses to metastasis. By studying androgen-independent lymphoid nodule carcinoma of the prostate (LNCaP) cells induced to apoptosis by serum elimination, we identified the activation of a non-selective cationic channel of 23pS conductance that promotes incoming $\mathrm{Ca}^{2+}$ currents, as well as apoptosis final stages. arp2cDNA was isolated and identified to be of the same cell type, and mRNA was expressed in Xenopus laevis oocytes, which was found to be associated with the activation of incoming $\mathrm{Ca}^{2+}$ currents and induction to apoptosis. CDNA, which encodes the ARP2 protein, was overexpressed in LNCaP.cells and Chinese hamster ovary cells, which induced apoptosis. Our evidence suggests that protein ARP2 overexpression and transit to the cell membrane allows an increased $\mathrm{Ca}^{2+}$ incoming current that initiates the apoptosis process in epithelial-type cells whose phenotype shows resistance to programmed cell death.

KEY WORDS: Apoptosis. ARP2 protein. Epithelial carcinoma. Prostate cancer.

\section{Introduction}

Cancer is a multifactorial disease and the second cause of death of general population in the world. Its causality is related to lifestyle, genetic predisposition and psychological and mood states of individuals. ${ }^{1}$ The prevalence of cancer has increased in recent years, and it is therefore a health problem that demands a very high level of attention. ${ }^{2,3}$ In males, the highest rates of cancer incidence occur in the prostate, lung, bronchi, colon, rectum and urinary bladder; in females, in the breast, lung, bronchi, colon, rectum, uterus and thyroid gland. The above is an indicator that the most common types of cancer in men and women, respectively, are prostate and breast cancer. ${ }^{4}$ In children, the highest incidence of cancer is observed in the bone marrow, brain and lymph nodes. ${ }^{5,6}$
Epithelial cancer is one of the most aggressive types. Particularly in prostate cancer, the treatment will depend on the stage the disease is identified at; however, it is very common for it to progress and develop a phenotype of apoptosis resistance and, therefore, of hormone independence, which makes for cells to continue proliferating until metastasis is reached, hence the development of new therapeutic strategies that prevent the disease from reaching advanced stages being essential.

During the process of apoptosis of numerous cell types, a sustained increase in cytoplasmic $\mathrm{Ca}^{2+}$ कैas been defined as a determinant in the onset of programmed cell death. ${ }^{7}$ Considering this rationale $>$ for years we have worked on the study of the mechanisms of cytoplasmic calcium homeostasis coftrol and the impact of $\mathrm{Ca}^{2+}$ altered level in various cell-and neoplastic types.
Correspondence:

*Jaime Mas-Oliva

E-mail: jmas@ ifc.unam.mx
Date of reception: 25-03-2019

Date of acceptance: 27-03-2019

DOI: 10.24875/GMM.M20000340
Gac Med Mex. 2019;155:504510

Contents available at PubMed

www.gacetamedicademexico.com

0016-3813/C 2019 Academia Nacional de Medicina de México, A.C.. Published by Permanyer. This is an open access article under the CC BY-NG-ND license (http://creativecommons.org/licenses/by-nc-nd/4.0/). 
We have been able to demonstrate that an increased level of cytoplasmic calcium results in the onset of programmed cell death in Chinese hamster epithelial cell lines of prostate and ovarian cancer. In this sense, our research group discovered a nonselective cationic channel permeable to $\mathrm{Ca}^{2+}$ with 23pS-conductance, expressed under conditions of induced apoptosis by removing serum from the culture medium in androgen-independent lymph node carcinoma of the prostate (LNCaP) cells. ${ }^{8}$ In addition, it was also possible to isolate the complementary DNA (cDNA) from LNCaP cells that encodes apoptosis regulatory protein 2 (which we called ARP2), which, when overexpressed, induces apoptosis in Xenopus laevis oocytes and androgen-independent LNCaP cells, from which ARP2 was originally isolated. ${ }^{9}$ ARP2 overexpression was shown to induce Chinese hamster ovary cell apoptosis. These findings demonstrate that $\mathrm{Ca}^{2+}$ increased levels are an indispensable condition to initiate apoptosis in various epithelial cell lines, and this protein could therefore constitute an excellent tool in the future in the treatment of the disease by preventing progression to the advanced stages that culminate with a metastatic process.

\section{Prostate cancer}

Prostate cancer is the second leading cause of cancer-related death in the United States and the fifth in the world. ${ }^{10-12}$ The prevalence of this disease increases with increasing age. Prostate cancer is found during autopsy in more than half of men older than 50 years in the United States, in spite of this disease beimng the cause of death only in $3 \%$. It is an asymptomatic disease until the appearance of metastatic lesions that are usually discovered in bone tissue. Initial therapies for its treatment include surgery, radiation, and use of 5-alpha reductase inhibitors, which promotes the formation of more potent androgens from testosterone. ${ }^{13}$ Initial treatment methods often cause sexual, urinary and intestinal dysfunction. ${ }^{14}$

From the molecular point of view, this disease manifests itself at early and late stages. In the former, prostate cell proliferation is slow and dependent on androgens, so that during treatment with chemotherapeutic agents, the cells manage to repair the damage and continue to proliferate. Over time, cells become independent of androgenic hormones to proliferate, which culminates in the development of metastases, leading to patient death. ${ }^{15}$

\section{Apoptosis and disease}

Programmed cell death or apoptosis is an intrî̀ sic cellular event of relevant importance in processes such as cell homeostasis, embryonic development and onset and maintenance of several diseases such as cancer and atherosclerosis. ${ }^{16,17}$ This mechanism develops through two pathways; the cell death receptor and the mitochondrial pathway..$^{18}$ In turn, the apoptotic process develops in several stages: the first one is related to the stimuli that trigger programmed cell death, the second involves the signal transduction processes, in the third, effector enzymes that take care of cell disassembly, such as active caspases, participate and, finally, in the fourth, chromatin . densation, DNA degradation and apoptotic body formation occurs. ${ }^{18,19}$

There are various apoptotic pathways, such as the extrinsic or death receptor pathway, whose initiating caspase is caspase 8 , and the intrinsic or mitochondrial pathway, which has cytochrome $\mathrm{C}$ as intermediary protein and caspase 9 as initiator. Both can converge in the set of effector caspases, mainly caspases 3 and 7 , which are activated through self-processing or caseade activation, whereby caspases themselves are self-activated and activated between each other. ${ }^{20,21}$ There is another alternative pathway called the perforin-granzyme pathway, ${ }^{22,23}$ which corresponds to an important serine protease complex in apoptosis that is induced by cytotoxic $T$ cells by activating independent caspase pathways.

\section{$\mathrm{Ca}^{2+}$ as the second determining messenger} in the apoptotic process

Variations in intracellular $\mathrm{Ca}^{2+}$ concentration promote the onset of cellular events such as the regulation of metabolism, mitosis, secretion of neurotransmitters and hormones, as well as the contraction of myofilaments, and therefore it is considered a second messenger that is determinant for cell functions. ${ }^{24,25} \mathrm{Ca}^{2+}$ levels are also involved in the regulatory mechanisms of apoptotic programmed cell death. ${ }^{26,27} \mathrm{~A} \mathrm{Ca}^{2+}$ level higher than basisal is considered highly toxic, since it generates the activation of proteases and phospholipases that participate in cell disassembly. ${ }^{28}$ The increase in $\mathrm{Ca}^{2+}$ can occur at early and late stages of apoptosis, through the outflow of $\mathrm{Ca}^{2+}$ from the endoplasmic reticulum and $\mathrm{Ca}^{2+}$ inflow to the cytoplasm through channels activated by $\mathrm{Ca}^{2+}$ release. ${ }^{7,29}$ It is necessary taking into account that part of intracellular $\mathrm{Ca}^{2+}$ moves to the endoplasmic 
A

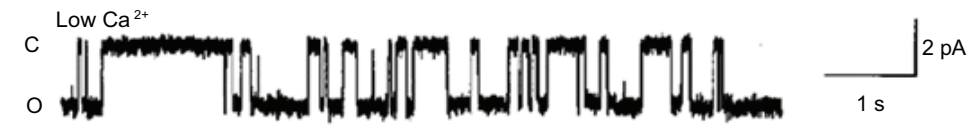

B

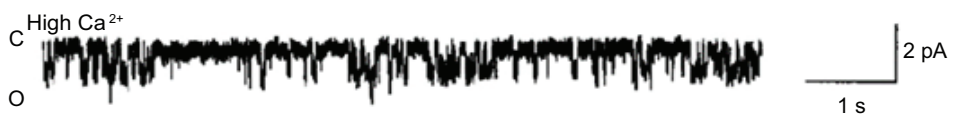

C

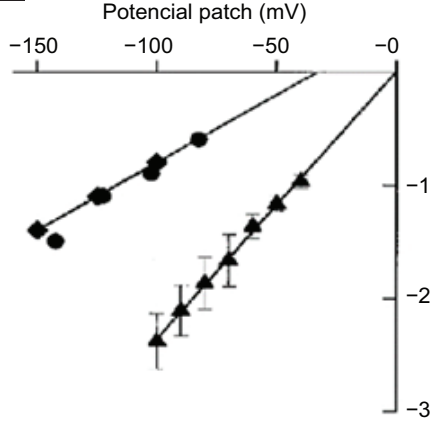

D

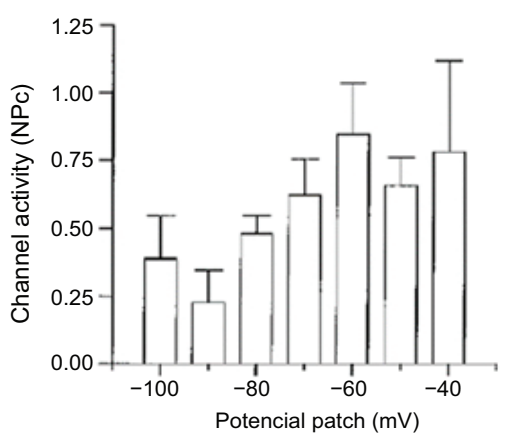

Figure 1. Characterization of ion channels associated with the second $\mathrm{Ca}^{2+}$ increase. A: Simple channel current records in the adhered cell configuration with a potential patch of $-100 \mathrm{mV}$ and $\mathrm{Na}^{+}-\mathrm{Ca}^{2+}$ solution; B: Simple channel records with $110 \mathrm{mM} \mathrm{CaCl}$ in the pipette solution and a potential patch of $-100 \mathrm{mV}$. The closed $(C)$ and open $(O)$ levels are indicated on the left side of the record; C: Current-voltage curves obtained in $\mathrm{Na}^{+} \mathrm{Ca}^{2+}(\mathbf{\Delta})$ solution, $110 \mathrm{mM} \mathrm{CaCl}{ }_{2}(\bullet)$ or $110 \mathrm{mM}$ calcium glutamate $(\bullet)$ as charge carriers; $\mathbf{D}$ : In the indicated membrane potentials $(n=4)$, mean \pm standard deviation of basal state activity of the 23pS channel is shown. Taken from reference 8.

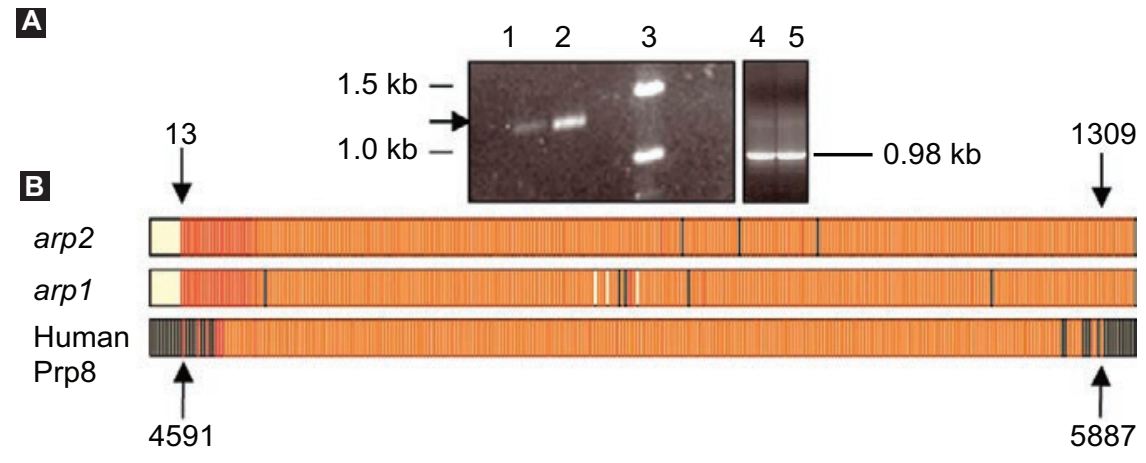

Figure 2. arp1 and arp2 cloning A: $1 \%$ (w/v) agarose, arp2 polymerase chain reaction products. Lane 1, product of cells growing in the presence of serum (control). Lane 2, product of cell cultures in the absence of serum. Lane 3, molecular weight markers (GIBCO BRL, DNA $1 \mathrm{~kb}$ ). Lanes 4 and 5, GAPDH controls; B: arp1 and arp2 cDNA multiple alignment with human Prp8 cDNA. Nucleotides 4591-5887 correspond to the human Prp8 region that overlaps with arp1 and arp2 cDNA sequences. The black lines indicate the nucleotides that do not show homology with cDNAs. The yellow spaces between the red lines correspond to nucleotide empty spaces between cDNAs. The black arrows point at arp1 andarp2 nucleotides 13 and 1309 and Prp8 nucleotides 4591 and 5887. Taken from reference 9.

reticulum through the endoplasmic reticulum calcium pump and that $\mathrm{Ca}^{2+}$ is released from these stores by inositol 1,4,5 triphosphate receptors or ryanodine receptors. Additionally, in various intracellular organelles (such as the Golgi apparatus, nucleus and mitochondria) there are specialized systems for $\mathrm{Ca}^{2+}$ transport. ${ }^{30}$

Calcium enters the cell through transmembrane proteins called calcium channels. ${ }^{31}$ Calcium passes through the channels by means of different mechanisms, depending on the type of channel or voltage, or through receptors; these pathways do not require energy, unlike calcium pumps, which release cytoplasmic calclum to the exterior of the cell at the expense of the use of adenosine triphosphate.

In collaboration with Dr. Agustín Guerrero of "GiNVESTAV, in the laboratory of the Institute of Cellular Physiology, National Autonomous University of Mexi$\mathrm{co}$, for the obtainment of electrophysiological records, the membrane fixation technique (patch clamp) fand single cell simultaneous $\mathrm{Ca}^{2+}$ measurements were combined, with the purpose of studying the activation of $\mathrm{Ca}^{2+}$-permeable channels using two different inducers: an ionophore (ionomycin) and serum elimination. ${ }^{8}$ 

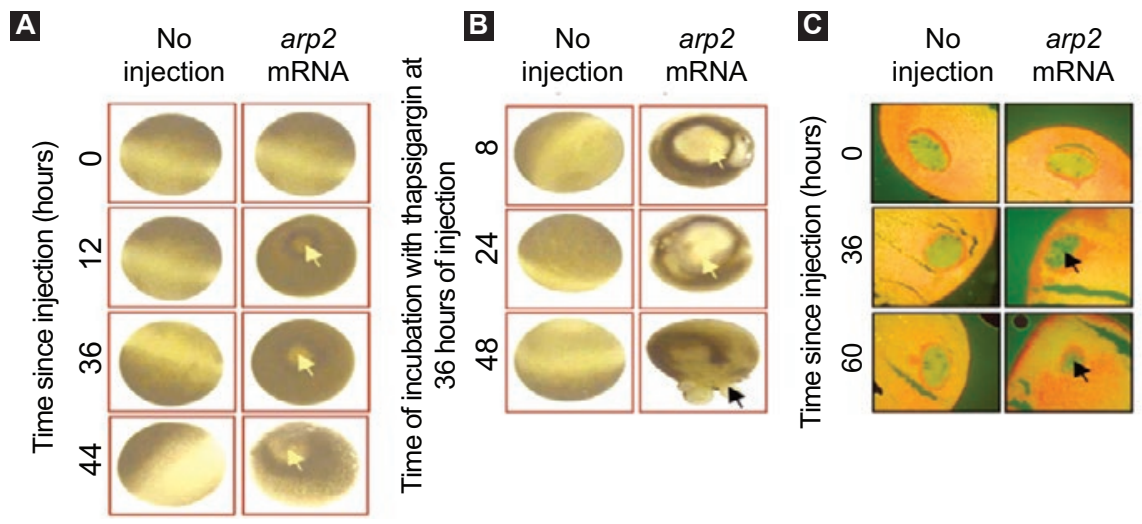

Figure 3. Xenopus laevis oocytes morphological apoptosis-related changes after arp2 mRNA injection; A: Apoptosis induction in Xenopus'laevis oocytes by arp2 mRNA microinjection. Vertical columns correspond to oocytes that did not receive injection and oocytes injected witharp2 mRNA. Horizontal lines show injection times (0,12, 36, 44 hours). The yellow arrows show the blisters formed; B: Cell death progression in Xenopus laevis oocytes injected with arp2 mRNA and incubation with $5 \mu \mathrm{M}$ of thapsigargin. Vertical columns show control oocytes that did not receive injection and oocytes injected with $m R N A$. Horizontal lines show incubation times with thapsigargin at 36 hours of injection and 8, 24, and 48 hours of incubation with thapsigargin; C: Morphological changes in the nucleus of Xenopus laevis oocytes observed after arp2 mRNA injection. Vertical columns show histological sections of non-injected oocytes and oocytes injected with arp2 $m R N A$. Horizontal lines show incubation time after mRNA injection (0, 36, 60 hours). The black arrows show chromatin condensation. Taken from reference 9.

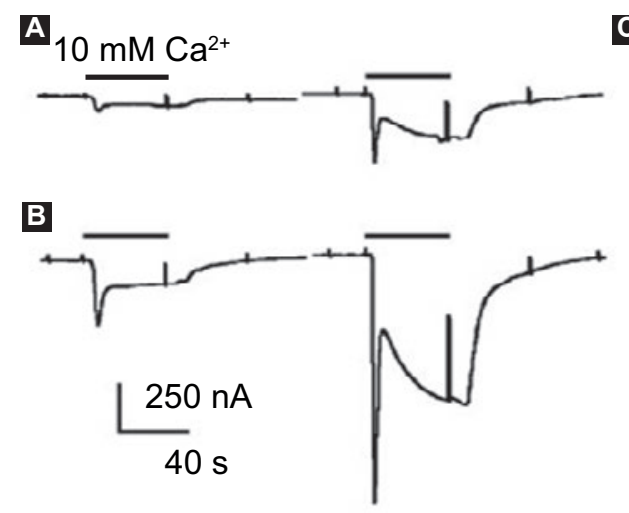

C

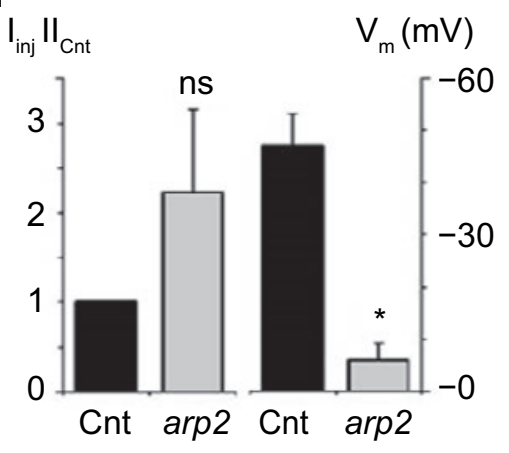

Figure 4. arp2 mRNA functional expression in Xenopus laevis oocytes. Ion currents generated by two consecutive pulses of $10 \mathrm{mM} \mathrm{Ga}^{2+}$ in Ringer-Mg ${ }^{2+}$ solution after oocyte incubation in the absence of $\mathrm{Ca}^{2+}$ and in the presence of $5 \mu \mathrm{M}$ of thapsigargin; $\mathrm{A}$ : Incoming currents generated in a non-injected control oocyte; B: Current in an oocyte injected with mRNA arp2. Histogram showing the mean \pm standard deviation of the current generated in control oocytes $(n=3)$ and oocytes injected with arp2 mRNA $(n=6)$. Changes in resting potential $(V m)$ observed between the different groups of oocytes (eight controls and six injected) are also shown. All oocytes of this figure were from the same donor; similar results were obtained from a second frog. Cnt $=$ control, $n s=$ not significant, ${ }^{*} p \leq 0.05$. Taken from reference 9 .

The latter deprives the cells from essential nutritional components such as proteins, growth factors and vitamins, inducing cells to death. ${ }^{32,33}$

The results demonstrated the activation of a non-selective and $\mathrm{Ca}^{2+}$-permeable cationic channel with 23pS-conductance. $\mathrm{Ca}^{2+}$ increased levels induced cells to apoptosis, which demonstrated that activation of this channel promotes the development of LN-CaP cells programmed death, which in turn constitutes an important finding for programmed death induction in this cell type (Fig. 1).

Continuing with this line of research, in our group, cDNAarp2, which codes for ARP2 of androgen-independent $\mathrm{LNCaP}$ cells, and which were induced to apoptosis by serum removal, was isolated, identified and characterized. ${ }^{9}$ The sequence of this protein shows homology with the splicing factor prp8 (a component of the spliceosome) $)^{34}$ and proapoptotic functions in different cell types (Fig. 2). The alternative-type splicing mechanism is defined as a property that prevails in higher organisms to produce multiple proteins from a simple gene. ${ }^{35,36}$ Prp8 protein ubiquitin-binding activity suggests that some splicing factors- - for pre-mRNA can be ubiquitinated to have an interaction with Prp8. ${ }^{37}$

Xenopus laevis frog oocytes injected with arp2 mRNA showed blistering after 12 hours of injection; these morphological changes were observed to increase when the oocytes are treated with thapsigargin (Fig. 3). It was also possible to observe that the 

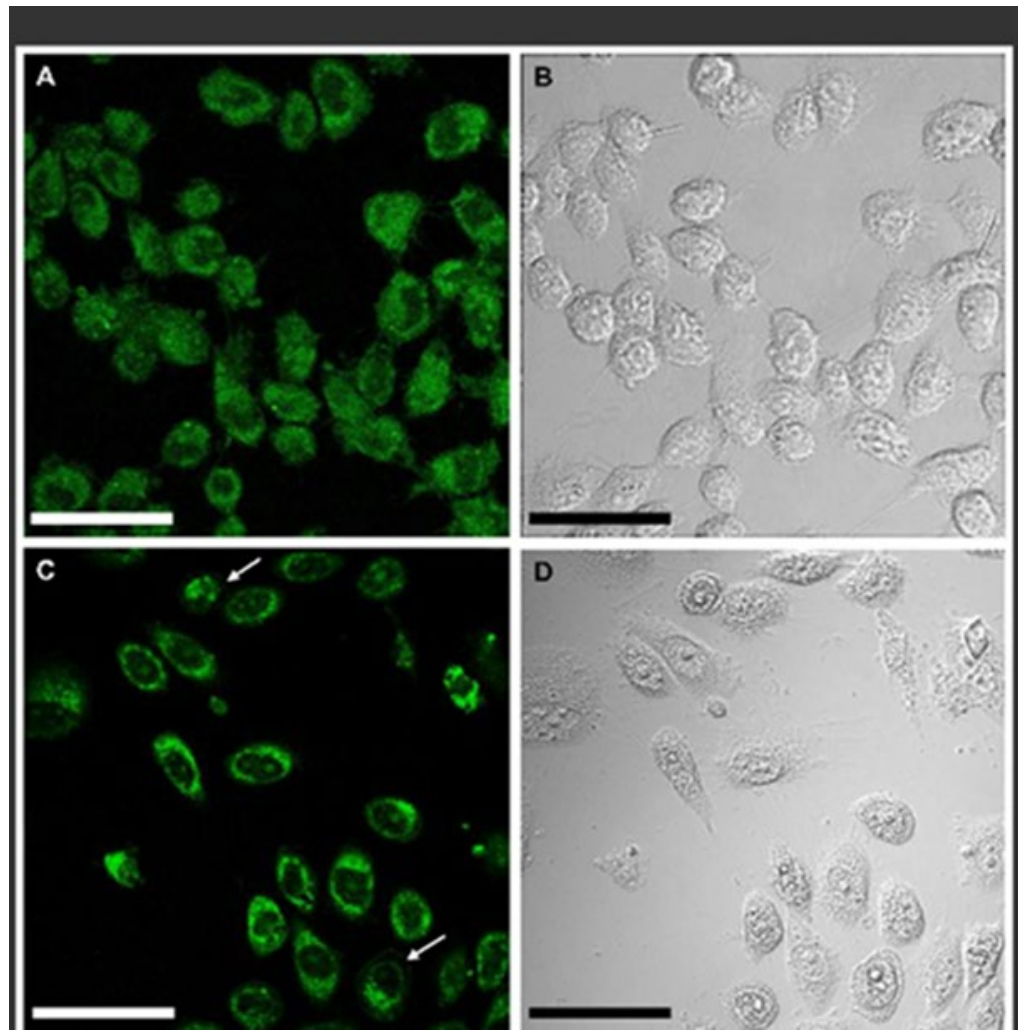

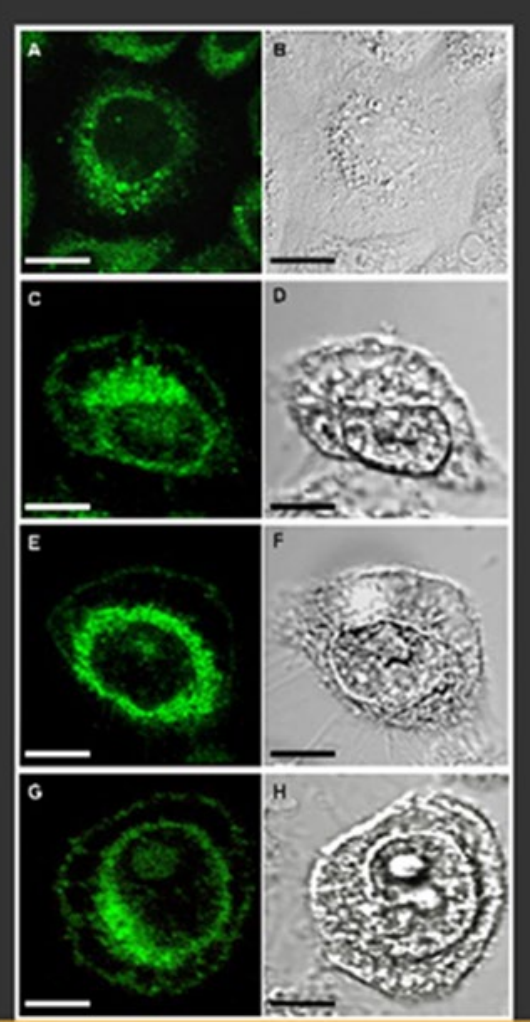

Figure 5. Confocal microscopy of the ARP2 fusion protein expressed in Chinese hamster ovary (CHO) cells. CHO cells transfected with-egfp cDNA were observed at 24 hours post-transfection. A: Differential interference contrast microscopy; B: $\mathrm{CHO}$ cells transfected with arp2-egfp cDNA were also observed 24 hours post-transfection; C: Differential interference contrast microscopy; D: Bar scale: 50 um. White arrows indicate that ARP2 is localized in the perinuclear region. Right side: CHO cells transfected with arp2-egfp cDNA examined at 16, 24, 48 and 72 hours post-transfection (A, C, E and $\mathbf{G}$, respectively); same as above, but with differential interference contrast microscopy (B, $\mathbf{D}$, $\mathbf{F}$ and $\mathbf{H}$, respectively). Bar scale: $10 \mu \mathrm{m}$. Taken from reference 41.

oocytes suffered a decrease in the resting membrane potential: from a control value of $-46.8 \pm 6.6 \mathrm{mV}$ they went to $-5.9 \pm 3.4 \mathrm{mV}$ (5-8 oocytes, two frogs) (Fig. 4). Incubation of the cells with thapsigargin accelerated and increased morphological changes, with the loss of definition of the animal and plant poles being evident, which was observed 36 hours after injection with arp2 mRNA and eight hours after incubation with thapsigargin (Figure 3B).

The morphological changes and membrane depolarization observed in our study have been described in Xenopus laevis oocytes when injected with cytochrome $\mathrm{C}$ to trigger the apoptotic mechanism, ${ }^{38}$ as well as in oocytes injected with the Bcl-xs proapoptotic molecule. 9,39 Thapsigargin, a drug that depletes $\mathrm{Ca}^{2+}$ intracellular stores by the specific inhibition of endoplasmic reticulum $\mathrm{Ca}^{2+}$-ATPase, elicits the activation of cytoplasmic membrane-independent voltage channels (TRP, transient receptor potential). ${ }^{40}$

This way, we have gathered sufficient evidence that ARP2 is an apoptosis promoter in androgen-independent LNCaP cells and in Chinese hamster ovary epithelial cells, ${ }^{41}$ thus favoring $\mathrm{Ca}^{2+}$ sustained increases by directly interacting with $\mathrm{Ca}^{2+}$-permeable membrane channels or by presenting a membrane channel function. On the other hand, considering the homology of the cDNA sequence that encodes ARP2 with the Prp8 splicing factor, it is not yet known whether this protein could additionally have any participation in the assembly or functioning of the spliceosome or be related to alternative splicing regulation mechanisms of mRNAs that encode proteins of the apoptotic machinery. There is a study where the Prp8 protein was observed to bind to one of the androgen receptor domains of prostate cancer cells and that, consequently, could be intervening in its functionality during the development of the disease. ${ }^{42}$ Furthermore, some splicing factors that make up the spliceosome, such as the SNW1 factor, have been reported to be linked to the development of breast cancer. ${ }^{43}$

Continuing with the project, ARP2-encoding cBNA was cloned in an expression plasmid and transfected to androgen-independent LNCaP cells and Chinese hamster ovary cells. ARP2 overexpression induced the cells to develop apoptosis, with an importantimpact on cell viability and effector caspases 3 and 7 


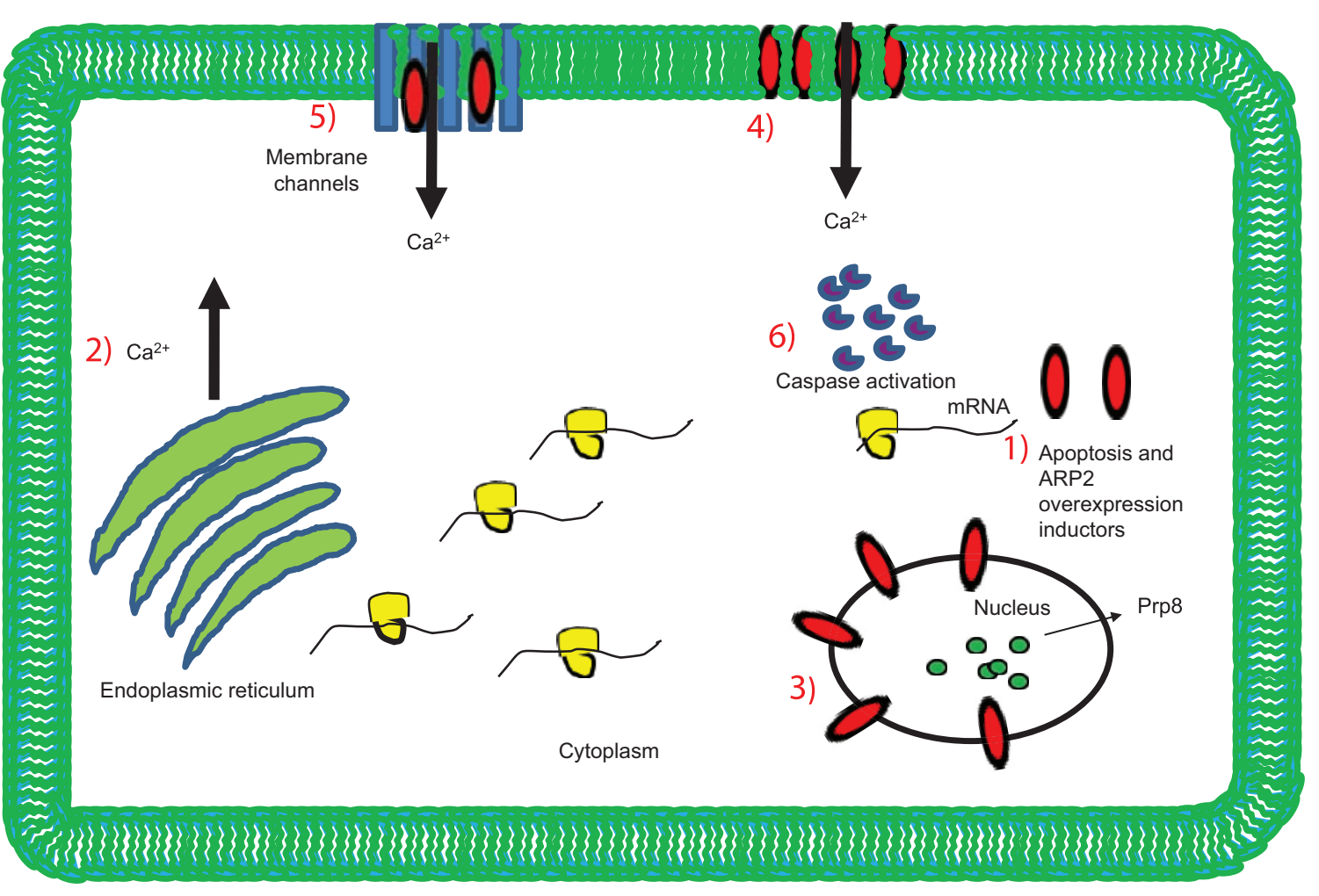

Figure 6. ARP2 action model. 1: Inducers of ARP2 apoptosis and overexpression; 2: ARP2 overexpression promotes an increase in Ca ${ }^{2+}$ that originates in the endoplasmic reticulum and cytoplasmic membrane; 3: ARP2 localized in the perinuclear membrane in interaction with the spliceosome complex, which promotes $\mathrm{Ca}^{2+}$ inflow; 4: ARP2 inserting into the cytoplasmic membrane and thereby forming possible membrane channels or regulating the activation of $\mathrm{Ca}^{2+}$-permeable channels (5): these $\mathrm{Ca}^{2+}$ inflows favor spliceosome complex activity and the development of the apoptosis mechanism (6).

activation, which are comparable results to those of starving cells treated with ionomycin ${ }^{41}$ (Fig. 5). In this study, using confocal microscopy, it was possible to demonstrate that ARP2 is initially located in the perinuclear region of cells and migrates over time to the plasma membrane ${ }^{41}$ (Fig. 5). Taking into account our results, we consider that ARP2 is inserted into the plasma membrane, with a function similar to that of a membrane channel, thus constituting a valuable target to modulate $\mathrm{Ca}^{2+}$ flow and concentration in the cytoplasm of epithelial cancer cells that show an apoptosis-resistant phenotype ${ }^{41}$ (Fig. 6).

\section{Perspectives}

The apoptosis mechanism in malignant cell resistant phenotypes has been the subject of extensive study in recent years. Due to the strong impact of cancer development, implementation of successful molecular strategies that support treatments against this disease is urgent. Our group has demonstrated that ARP2 protein overexpression induces programmed cell death in different cell types: androgen-independent lymphoid nodule prostate cancer cells, from where it was originally isolated, Chinese hamster ovary cells, embryonic human kidney cells and côronary artery endothelial cells (data not shown).

Given the collected experimental evidence, we consider that ARP2 could be contributing during its overexpression to the increase in $\mathrm{Ca}^{2+}$ intracellular levels as a messenger molecule or as a protein inserted in the membrane that favors $\mathrm{Ca}^{2+}$ inflow. In addition to being found in the membrane region, we also- 0 served its perinuclear localization, and due to the homology with the Prp8 factor, there is the possibility that it participates in the alternative splicing mechanisms of pro-apoptotic molecules. ${ }^{44-46}$ In this sense, and taking into account that transcription through alternative splicing mechanisms are molecular procêsses that are highly regulated by $\mathrm{Ca}^{2+}$ intracellular level, among other factors, ${ }^{47,48}$ it is feasible to think that ARP2 might have a double function: in the control of plasma $\mathrm{Ca}^{2+}$ flow and in alternative splicing molecular mechanisms.

Based on the evidence that cell death genescare deregulated in cancer, a phenomenon that is associated with the control of their alternative splicing patterns, it is reasonable thinking that the apoptosis proeess 
occurs as a positive response to chemotherapy. ${ }^{49}$ If we take into account that anticancer drugs efficacy may also depend on apoptosis activation or on a form of cell-senescence acute induction, we consider that ARP2 protein overexpression could potentially be used as a new tool in the treatment epithelial-type cancer.

\section{References}

1. Vineis $P$, Wild $C P$. Global cancer patterns: causes and prevention. Lancet. 2014;383:549-557.

2. Siegel R, Naishadham D, Jemal A. Cancer statistics, 2013. CA Cancer J Clin. 2013;63:11-30.

3. Hossein-Hassanpour S, Dehghani M. Review of cancer from perspective of molecular. J Cancer Res Pract. 2017:4:127-129.

4. Siegel RL, Miller KD, Jemal A. Cancer statistics, 2016. CA Cancer J Clin. 2016:66:7-30

5. Schottenfeld D, Fraumeni JF. Cancer epidemiology and prevention. Inglaterra: Oxford Scholarship Online; 2006.

6. Yoo KY, Shin HR. Cancer epidemiology and prevention. Korean J Epidemiol. 2003;25:1-15.

7. Pinton P, Giorgi C, Siviero R, Zecchini E, Rizzuto R. Calcium and apoptosis: ER-mitochondria $\mathrm{Ca} 2+$ transfer in the control of apoptosis. Oncogene. 2008;27:6407-6418.

8. Gutiérrez AA, Arias JM, García L, Mas-Oliva J, Guerrero-Hernández A Activation of a Ca2+ permeable cation channel by two different inducers of apoptosis in a human prostatic cancer cell line. J Physiol. 1999;15:95-107.

9. Tapia-Vieyra JV, Arellano RO, Mas-Oliva J. ARP2 a novel protein involved in apoptosis of LNCaPcells shares a high degree homology with splicing factor Prp8. Mol Cel Biochem. 2005;269:189-201.

10. Ferlay J, Soerjomataram I, Dikshit R, Eser S, Mathers C, Rebelo M, et al. Cancer incidence and mortality worldwide: sources, methods and major patterns in GLOBOCAN 2012. Int J Cancer. 2015:136:E359-E386.

11. Dall'Era MA, Albertsen PC, Bangma C, Carroll PR, Carter HB, Cooperberg MR, et al. 2012. Active surveillance for prostate cancer: a systematic review of the literature. Eur Urol. 2012:62:976-983.

12. Siegel RL, Miller KD, Jemal A. Cancer statistics, 2015. CA Cancer J Clin. 2015;65:5-29

13. Thompson IM, Goodman PJ, Tangen CM, Lucia MS, Miller GJ, Ford LG et al. The influence of finasteride on the development of prostate cancer. N Engl J Med. 2003;349:215-224.

14. Talcott JA. In the clinic. Prostate cancer. Ann Intern Med. 2015;163:ITC1 ITC12.

15. Quinn DI, Sandler HM, Horvath LG, Goldkorn A, Eastham JA. The evoIution of chemotherapy for the treatment of prostate cancer. Ann Oncol. 2017;28:2658-2669.

16. Kerr JF, Wyllie AH, Currie AR. Apoptosis: a basic biological phenomenon with wide-ranging implications in tissue kinetics. $\mathrm{Br} J$ Cancer. 1972;26:239-257.

17. Tapia-Vieyra JV, Delgado-Coello B, Mas-Oliva J. Atherosclerosis and cancer; a resemblance with far-reaching implications. Arch Med Res. 2017;48:12-26

18. Chen M, Wang J. Initiator caspases in apoptosis signaling pathways. Apoptosis. 2002;7:313-319.

19. Cooper KF. Till death do us part: the marriage of autophagy and apoptosis. Oxidative Med Cell Longevity. 2018;1:1-13.

20. Fulda S, Debatin KM. Extrinsic versus intrinsic apoptosis pathways in anticancer chemotherapy. Oncogene. 2006;25:4798-4811.

21. Hassan M, Watari H, AbuAlmaaty A, Ohba Y, Sakuragi N. Apoptosis and molecular targeting therapy in cancer. Biomed Res Int. 2014;2014:150845.

22. Elmore S. Apoptosis: a review of programmed cell death. Toxicol Pathol. 2007:35:495-516.
23. Adams JM. Ways of dying: multiple pathways to apoptosis. Genes-Dev. 2003;17:2481-2495.

24. Mason RP. Calcium channel blockers, apoptosis and cancer: is there a biologic relationship? J Am Coll Cardiol. 1999;34:1857-1866.

25. Clapham DE. Calcium signaling. Cell. 2007;131:1047-1058.

26. Rizzuto R, Pinton P, Ferrari D, Chami M, Szabadkai G, Magalhães P $\sqrt{G}$ et al. Calcium and apoptosis: facts and hypotheses. Oncogene. 2003;22:8619:8627.

27. Giorgi C, Romagnoli A, Pinton P, Rizzuto R. Ca2+ signaling, mitochondria and cell death. Curr Mol Med. 2008;8:119-130.

28. Fariss MW, Pascoe GA, Reed DJ. Vitamin E reversal of the effect of extracellular calcium on chemically induced toxicity in hepatocytes. Science. 1985;227:751-754.

29. Pinton P, Rizzuto R. Bcl-2 and $\mathrm{Ca} 2+$ homeostasis in the endoplasmic reticulum. Cell Death Differ. 2006:13:1409-1418.

30. Görlach A, Bertram K, Hudecova S, Krizanova O. Calcium and RÖS: a mutual interplay. Redox Biol. 2015;6:260-271.

31. Tapia-Vieyra JV, Mas-Oliva J. Apoptosis and cell death channels in prostate cancer. Arch Med Res. 2001;32:175-185.

32. Schamberger CJ, Gerner C, Cerni C. Caspase-9 plays a marginal role in serum starvation-induced apoptosis. Exp Cell Res. 2005;302:115-128.

33. Braun F, Bertin-Ciftci J, Gallouet AS, Millour J, Juin P. Serum-hutrient starvation induces cell death mediated by Bax and Puma that is counteracted by $\mathrm{p} 21$ and unmasked by $\mathrm{Bcl}-\mathrm{xL}$ inhibition. Plosone. 2011;6:e23577.

34. Kelemen O, Convertini P, Zhang Z, Wen Y, Shen M, Falaleeva M, vet al. Function of alternative splicing. Gene. 2017;514:1-30.

35. Black DL. Mechanisms of alternative pre-messenger RNA splicing. Annu Rev Biochem. 2003;72:291-336.

36. Blencowe BJ. Alternative splicing: new insights from global analyses. Cell. 2006;126:37-47.

37. Bellare P, Kutach AK, Rines AK, Guthrie C, Sontheimer EJ. Ubiquitin binding by a variant Jab1/MPN domain in the essential pre-mRNA splicing factor Prp8p. RNA. 2006;12:292-302.

38. Bhuyan AK, Varshney A, Mathew MK. Resting membrane potentiatas a marker of apoptosis: studies of xenopus oocytes microinjected with-cytochrome c. Cell Death Differ. 2001;8:63-69.

39. Braun T, Dar S, Vorobiov D, Lindenboim L, Dascal N, Stein R. 2003. Expression of Bcl-x(S) in xenopus oocytes induces BH3-dependent and caspase-dependent cytochrome $\mathrm{c}$ release and apoptosis. Mol Cancer Res. 2003;1:186-194.

40. Boulay G, Zhu X, Peyton M, Jiang M, Hurst R, Enrico S, et al. CPिning and expression of a novel mammalian homolog of Drosophila transient receptor potential (Trp) involved in calcium entry secondary to activation of receptors coupled by the $G_{q}$ class of $G$ protein. $J$ Biol Chem. 1997;272:29672-29680.

41. Mas-Oliva J, Navarro-Vidal E, Tapia-Vieyra JV. ARP2, a novel pro-apoptotic protein expressed in epithelial prostate cancer LNCaP cells and epithelial ovary CHO transformed cells. PLoS One. 2014;9:e86089.

42. Wang D, Nguyen MM, Masoodi KZ, Singh $P$, Jing $Y$, O'Malley $K$, et al. Splicing factor Prp8 interacts with NES(AR) and regulates androgen receptor in prostate cancer cells. Mol Endocrinol. 2015;29:1731-1742.

43. Sato N, Maeda M, Sugiyama M, Ito S, Hyodo T, Masuda A, et al. 2015 . Inhibition of SNW1 association with spliceosomal proteins promotes apoptosis in breast cancer cells. Cancer Med. 2015;4:268-277.

44. Maniatis T, Tasic B. Alternative pre-mRNA splicing and proteome expansion in metazoans. Nature. 2002;418:236-243.

45. Schwerk C, Schulze-Osthoff K. Regulation of apoptosis by alternative pre-mRNA splicing. Mol Cell. 2005:19:1-13.

46. Moore MJ, Wang Q, Kennedy CJ, Silver PA. An alternative splicing network links cell-cycle control to apoptosis. Cell. 2010;142:625-636

47. Krebs $\mathrm{J}$. The influence of calcium signaling on the regulation of alternatives splicing. Biochim Biophys Acta. 2009;1793:979-984.

48. Tarn WY. Cellular signals modulate alternative splicing. J Biomed Sci. 2007; $14: 517-522$

49. Bracco L, Kearsey J. The relevance of alternative RNA splicing tocpharmacogenomics. Trends Biotechnol. 2003;21:346-353. 